\title{
Development of Mobile Application for K to 12 Mother Tongue Based-Multi Linguistic Education
}

\author{
Jessie T. Sunico \\ NCES, DepEd - Siargao Division \\ Philippines \\ Joey G. Escauso \\ SSCT - Del Carmen Campus \\ Philippines
}

\begin{abstract}
This article studies a learning management application called Mobile Application for $K$ to 12 Mother Tongue Based-Multi Linguistic Education. This mobile application is designed for a mobile interface to multiple environments and manageable to various infrastructure specifications using tablets and mobile phones. The study adopted the Rapid Application Development model and used the ISO 9126 standard to evaluate the application in terms of usability (4.4), functionality (4.1), and maintainability (4.1). In general, the result shows that the application got the respondent's high rate on the evaluated characteristics. Hence, the application indeed provides a convenient tool in which data and features are useful to the teacher and pupils and encourages unique learning opportunities.
\end{abstract}

Keywords:- Mother Tongue; Mobile Application; Learning Management Application; K to 12 Education.

\section{INTRODUCTION}

Numancia Central Elementary School (NCES) is a public school in Del Carmen, Siargao Island that offers K12 Curriculum Guide (CG). The Department of Education releases the K-12 Curriculum Guide (CG), reflects how the younger Filipinos are envisioned to confront the twentyfirst century [1]. Grade 3 teachers utilize a Curriculum Guide for Mother Tongue subject as a material/tool for teaching, optimizing its effectiveness. However, the school has insufficient learning materials to meet the competencies in the topics effectively. Thus, this project came to birth, aiming to develop a Mobile Application for K to 12 Mother Tongue Based-Multi Linguistic Education, with built-in topics to improve teacher effectiveness and boost pupil learning capabilities.

These Curriculum Guide and related policy documents regarding what sort of citizen's recent educational reforms intend to develop (Adarlo et al., 2016). Meanwhile, one of the most widely used educational inputs is the traditional approach. Yet, few are developed and evaluated scientifically with a dearth of programs targeting academic language to design and creating a research-based curriculum [2]. On the other hand, the perspective of an information and Communications Technology (ICT) integration specialist on how mobile devices and apps are being used in several primary schools improves pupils'

\author{
Grace Ann. B. Argana \\ BNHS, DepEd - Siargao Division \\ Philippines \\ Leonila L. Bermudes \\ SSCT - Del Carmen Campus \\ Philippines
}

literacy across a range of context and curriculum areas [3]. Further, Mobile technology has become popular worldwide with a broad range of users, including pupils from all education [4].

The cited studies state that using mobile devices nowadays is widespread and provides excellent educational learning capabilities, making the delivery of mobile learning a more realistic approach since it can provide just in time learning on the move [5]. With countless online resources, technology can help improve teaching. Teachers can use different applications or trusted online resources to enhance traditional teaching methods and keep pupils more engaged. However, the main challenges faced by the teachers is the unavailability of technologically-enhanced and localized learning materials. In so far, no existing tool yet duly integrated with an automated mobile application of the school ever had as learning topics is a concern. Hence, NCES looked forward to optimizing the way of doing in teaching services.

Interactive mobile learning platform enables real-time interactive discussion among pupils and lecturer through their tablet PCs and smartphones and facilitates classroom discussion of various sizes and styles, gathering opinions from all classmates in an organized manner that is conducive to effective and fruitful discussions [6]. With this, the researcher developed a mobile application that gives a better way of improving the present set up of the Curriculum Guide's way of teaching. Also, this application for Grade 3 Mother Tongue provides great opportunities for making learning more effective for everyone with different needs.

\section{OBJECTIVES}

The study's general objective is to design and develop a mobile application for the grade 3 teacher and pupils with an interactive mobile application and educational learning platform.

Specifically, it aims to:

$>$ Design and develop a mobile application with features such as:

- Week, quarter, lesson, quiz module;

- Video presentation;

- Print and E-mail output; 
- Whiteboard class updates using Jamboard;

> Implement mobile application in online learning class that would help to promote mobile application in educational learning technology;

$>$ Evaluate the application using the system evaluation tool parallel to the ISO 9126 standards as to usability, functionality, and maintainability.

\section{SIGNIFICANCE OF THE STUDY}

Teacher - Enable teacher as a new resource for communication platform tools in teaching with the pupils using a mobile application developed.
Pupils - To learn more in advance using mobile applications in educational learning and to modernize in the advent of technology.

\section{CONCEPTUAL FRAMEWORK}

Figure 1.0 below shows the Input-Process-Output (IPO) Model used in conceptualizing the development of the system application. The IPO Model was the framework used in the study, which involves various stages and processes to fully develop the system.

\begin{tabular}{|c|}
\hline INPUT \\
\hline $\begin{array}{c}\text { Knowledge Requirements: } \\
\text { - NCES, DepEd Siargao } \\
\text { Policies } \\
\text { Teachers and Pupils } \\
\text { Knowledge } \\
\text { Hardware Requirements: } \\
\text { - Windows } 10 \text { OS home single } \\
\text { language } \\
\text { - } 4.00 \text { GB installed memory } \\
\text { - RAM) } \\
\text { Intel Core Processor i3 or } \\
\text { - } \text { higher } \\
\text { 64-bit OS x64 based- } \\
\text { processor } \\
\text { - MS Wortware Requirements: } \\
\text { - Word press } \\
\text { - Appgeyser } \\
\text { - Adobe Photoshop } \\
\text { - Adobe premier } \\
\text { - Power Director } \\
\text { - Jamboard }\end{array}$ \\
\hline
\end{tabular}

Fig 1:- IPO Model
This IPO is the representation model used in the development of a mobile application. The development of the application requires the knowledge of the teacher and pupils for a better understanding of the development of the application. On the process stage, the designing and development of the application are being done. The System Development Life Cycle (SDLC) includes system conceptualization, planning, analyzing, designing, development, and integration with other components are considered. The application can be seen in the output process. The evaluation of the application is being done to ensure conformity to the standards as to usability, functionality, maintainability and of the mobile application.

\section{METHODOLOGY}

Rapid Application Development (RAD), a methodology of the System Development Life Cycle, was used in the study. Figure 2 below was used by the researchers to accomplish the requirement of the application. 


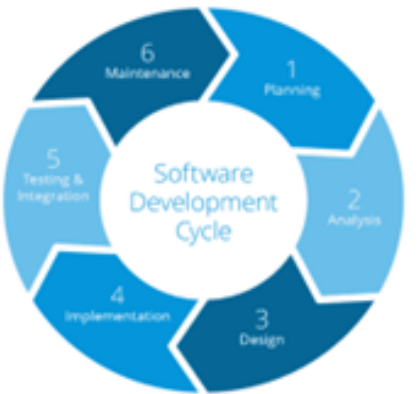

Fig 2:- Rapid application Development

\section{A. Analysis}

Figure 3 shows the current technical situation of the process. They observed the technique and strategy to determine the processes in Numancia Central Elementary School, especially in the delivery of instruction. The researcher studied the current system in school via interview and observation to the teachers and administrator. Also, the researcher conducted a group meeting to conduct brainstorming and sharing ideas on the conceptualization of the application. During the discussions, the scope of the application, the processes included, and the required data to execute the processes were identified, and the solution to the problems.

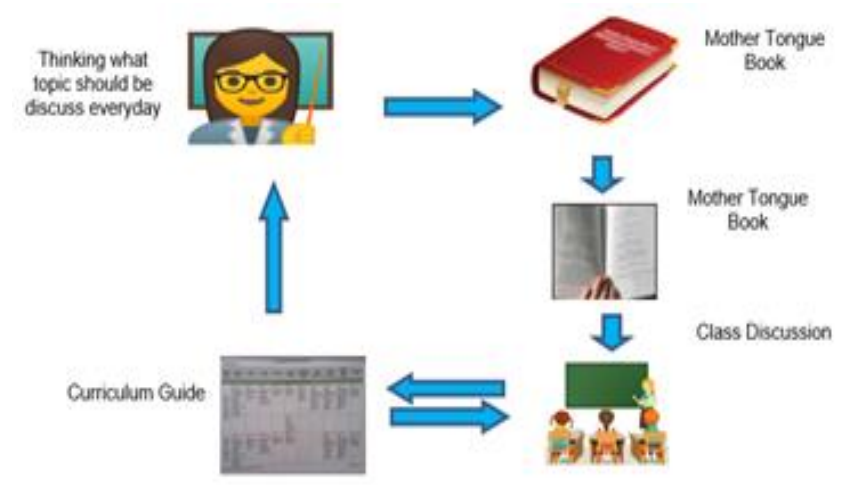

Fig 3:- Current Technical Situation

\section{B. Design}

Figure 4 shows the System Architecture. In designing, the researcher analyzes the application module's designs with the requirement that will address issues in classes of the identified gaps in the study. It utilizes the mobile interactive learning platform that provides materials tools for teaching in the school of Numancia Central Elementary School.

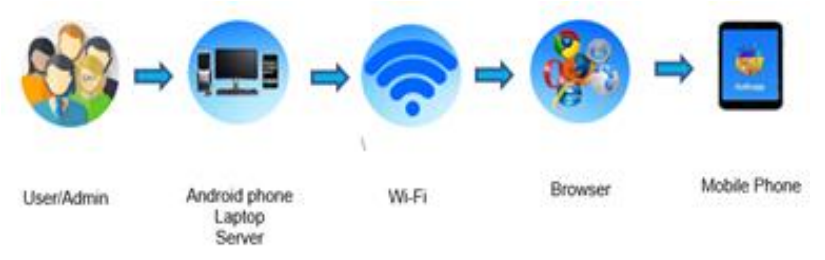

Fig 4:- System Architecture
In the system architecture, the researchers has developed the application guided based on the user's current system and preference, the researchers used recommended tools for the making of the application in terms of the interface design by the models. The researchers used adobe photoshop and power director as editing tools, adobe premiere for the video presentation editing. Appgeyser in converting to application and Jamboard as a whiteboard class for writing, draw an element, do the assignment, and share ideas through email and the email for the updates of pupils class of their discussions.

\section{Implementation}

The implementation was done on different tablets and mobile phones. A letter was sent and installation was done. The teachers and administrator of the NCES observed and accepted the implementation of the application.

\section{Evaluation}

The application's usability, functionality, and maintainability were evaluated based on the adopted tool from John Brooke (1986) and ISO 9126. The instrument consisted of two parts. Part I covered the items personal information of the employee. Part II focused on the items that determines the usability, functionality, and maintainability of the application.

The total number of the respondents in system evaluation was 30 , which are represented by pupils and teachers. Convenience sampling was used in identifying the respondents. A validation survey instrument was utilized by respondents in application evaluation.

\begin{tabular}{|c|c|c|}
\hline RESPONDENTS & $\mathbf{N}$ & PERCENTAGE \\
\hline Teachers & 10 & $33 \%$ \\
\hline Pupils & 20 & $67 \%$ \\
\hline Total & $\mathbf{3 0}$ & $\mathbf{1 0 0} \%$ \\
\hline
\end{tabular}

Table 1:- Distribution of Respondents

Table 1 shows the number of respondents. Thirty (30) persons evaluated the system application; to wit, ten (10) from the teachers and twenty (20) from the pupils. The proponents used the adjectival rating to determine the value of the result, the application using the indicators using the scale of one (1) - strongly disagree from the rates of $1.0-$ 1.7 , two (2) - disagree from the rates of $1.8-2.3$, three (3) - fair from the rates of $2.6-3.3$, four (4) - agree from the rates of $3.4-4.1$ and five (5) - strongly agree from the rates of $4.2-5.0$. 


\section{RESULTS AND DISCUSSION}

Teaching in learning through mobile devices using online is the best way of a platform presentation tool for the teacher to follow and connect the pupils in their subject course. Figure 5 shows the Splash Screen of the Application.

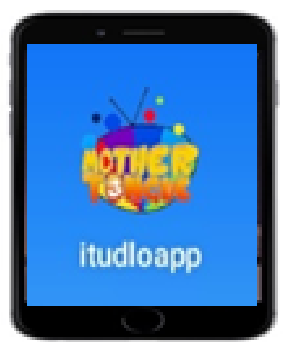

Fig 5:- Splash Screen

Figure 6 shows the Home Screen; that views the content and the menu screen of the application; this page is consists of buttons features serve as the user function in accessing the list content.

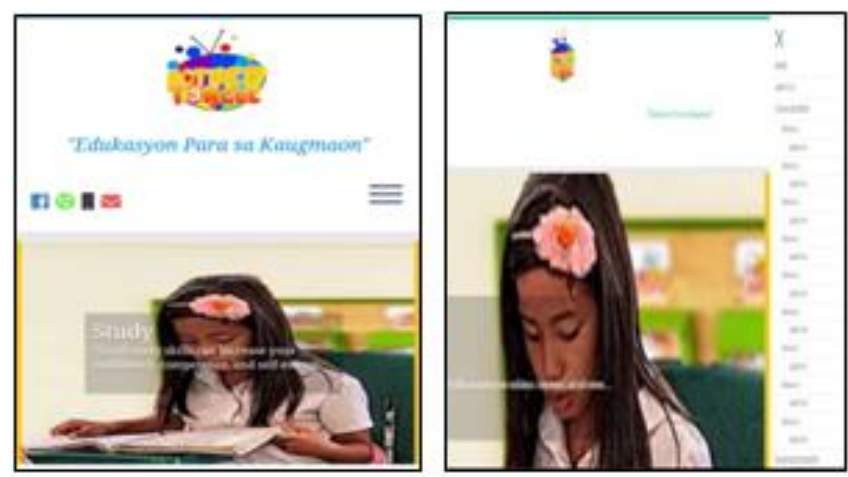

Fig 6:- Home Screen Figure

Figure 7 shows the whiteboard interface in which the user can access and enjoy the whiteboard feature. Just like a board, one can write, draw, insert an image, among others.

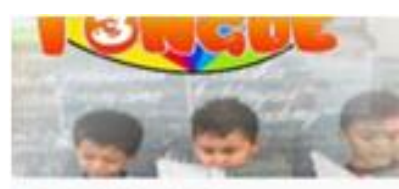

White Board For Class

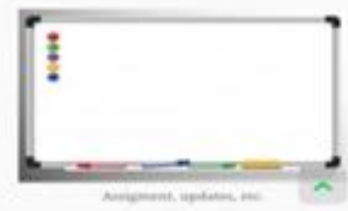

Fig 7:- White Board Interface

Figure 8 shows the attendance sheet interface. The pupils can click the attendance button, and they can take access to present attendance and show information detail content.
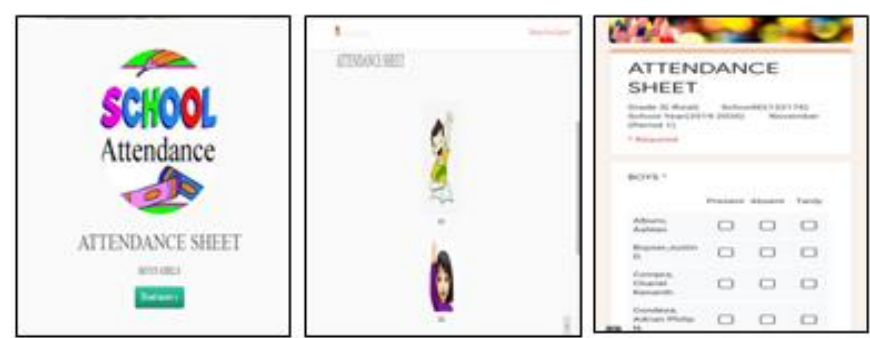

Fig 8:- Attendance Interface

Figures 9 and 10 show the video interface that the pupil can access video contents to learn their capabilities.

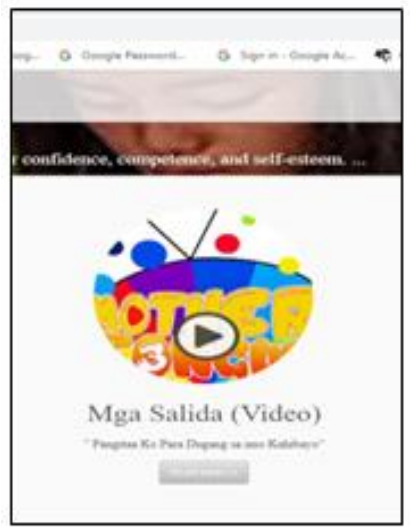

Fig 9:- Video Button

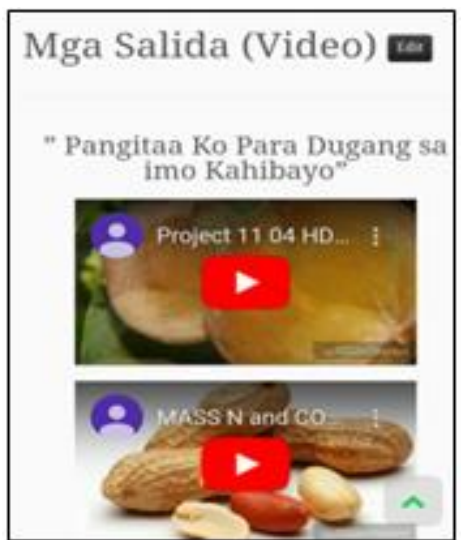

Fig 10:- Video Content

Figure 11 shows the quiz button. It allows pupils to access a test questionnaire.

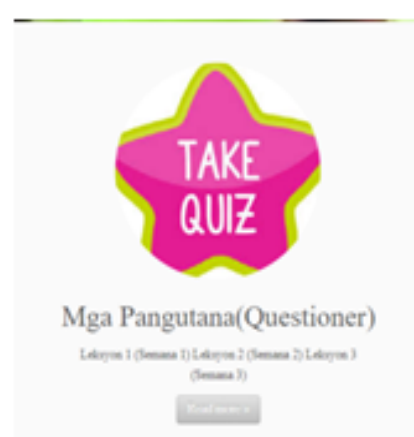

Fig 11:- Quiz Button 
Figure 12 shows the test questionnaire interface. It allows pupils to access the test questionnaire and take a quiz.

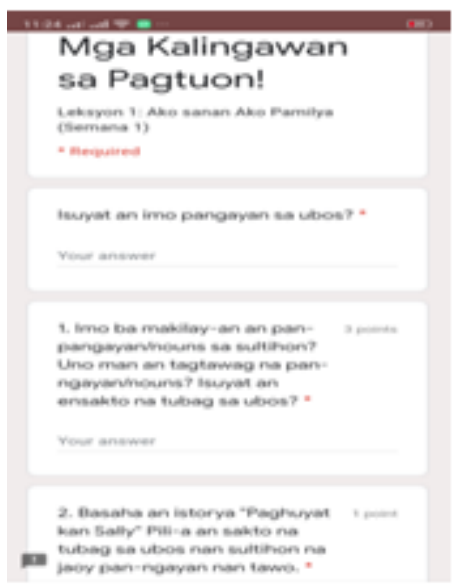

Fig 12:- Test Questionnaire

\section{EVALUATION}

The application was deployed and evaluated using the International Standard Association (ISO). In particular, it employed the ISO 9216 assessing application usability, functionality, maintainability. In Figure 13, under component 1 teachers, when asked if the application is likely to use frequently, users rated "Agree" with a mean score of (U1 - 4.4); when asked if the application was easy to use, a mean score of (U2 - 4.33) was obtained which also means "Agree." On various functions in this application were well integrated, a mean score of (U3 - 4.4) was obtained, on most people would learn to use this application very quickly, a mean of (U4 - 4.4). Respondents thought they are very confident in using the application evident from the standard (U5 - 4.5). Generally, the mean of the application's usability index is (MEAN - 4.4), which means that the respondent "Agree" that the application is usable.

USABILITY OF THE APPLICATION

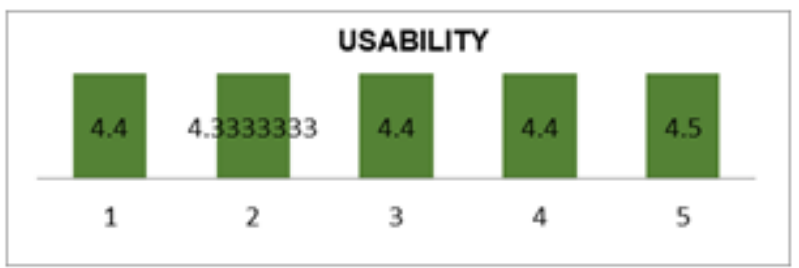

Fig 13:- Usability of the Application

In the functionality of the application as shown in figure 14, when asked if there are appropriate essential functions of the application, users rated "Agree" with a mean score of $(\mathrm{F} 1$ - 4.2). There is correctness of the functions and commands, a mean score of (F2 - 4.13), which means "Agree". Then next asked is the given software component or system does not typically function in isolation, a mean score of (F3 - 4.03), and the mobile application has met the institution appropriate laws and guidelines need to be complied with, with a mean score of (F4 - 4.03). The respondent thought that the application has security related to unauthorized access to the software function from the (F5 - 4.3). Generally, the mean of the application's functionality is (MEAN - 4.1), which means that the respondent agrees with its functionality.

FUNCTIONALITY OF THE APPLICATION

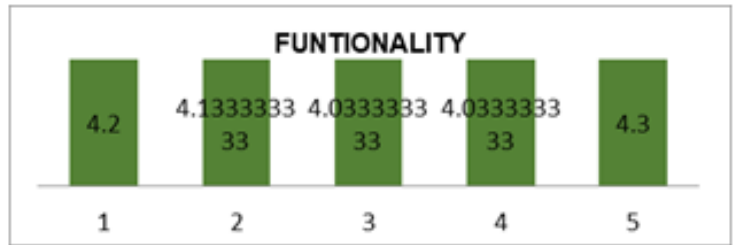

Fig 14:- Functionality of the Application

As shows in figure 15 and in the maintainability of the application, Under component 1, when asked if the mobile application can quickly identify the root cause of the feature within the software, the user rated "Agree" with a mean score (M1 - 4.26). When asked if the mobile application can sustain on updates to verify (test) an application change, a mean score of (M2 - 4.23) was obtained, which also means "Agree". In the item that can store an application/data changes, a mean score of (M3 4.36) was obtained. On the application that can change the data inside the application, a mean of (M4 - 4.2), asked if the mobile application has the capability of resources to store a massive amount of data, a mean score (M5 - 3.66), with the rate of "Strongly agree" asked if has the capability of speed to execute the process. Generally, the mean of the application's maintainability index is (MEAN - 4.1), which the respondent "Strongly Agree" that the application has the standard in terms of maintenance.

\section{MAINTABILITY OF THE APPLICATION}

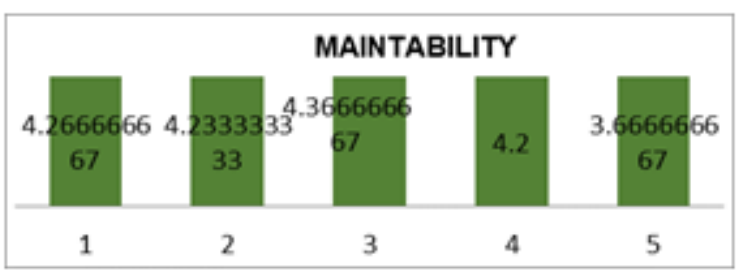

Fig 15:- Functionality of the Application

Table 2 shows the application evaluation result. It shows that the application got a Grand Mean of 4.2 with the adjectival rating of "Strongly Agree".

\begin{tabular}{|c|c|}
\hline $\begin{array}{c}\text { System Evaluation in } \\
\text { terms of: }\end{array}$ & Mean \\
\hline Usability & 4.4 \\
\hline Functionality & 4.1 \\
\hline Maintainability & 4.1 \\
\hline Grand Mean & $\mathbf{4 . 2}$ \\
\hline
\end{tabular}

Table 2:- Application Evaluation Result 


\section{CONCLUSION}

The researchers concluded that the application is beneficial to both teachers and pupils of Numancia Central Elementary School in terms of learning strategies in school, enhancing the pupils' effectiveness, and boosting the pupils' learning capabilities with the innovation made.

\section{RECOMMENDATIONS}

The recommendation of the application provides the user the straightforward way of time in teaching in Numancia Central Elementary School teachers for its friendly learning environment that will advance the pupils' education with the innovations made. Thus, it is recommended that:

The application should be uploaded to google play store for easy access to other end-users.

$>$ There must be a regular user training activities that will emphasize the pedagogical use of the application.

The administrator should coordinate with the google forms for the quiz and update information data in the youtube channel to edit a video presentation.

White Board for class updates, assignments, and communication through email to update every class assignment.

\section{REFERENCES}

[1]. Adarlo, G., \& Jackson, L. (2017). For Whom Is K-12 Education: A Critical Look into Twenty-First Century Educational Policy and Curriculum in the Philippines. In Educating for the 21st Century (pp. 207-223).

[2]. Zucker, T. A., Carlo, M. S., Landry, S. H., MasoodSaleem, S. S., Williams, J. M., \& Bhavsar, V. (2019). Iterative Design and Pilot Testing of the Developing Talkers Tiered Academic Language Curriculum for Pre-Kindergarten and Kindergarten. Journal of Research on Educational Effectiveness, 12(2), 274306.

[3]. Clarke, J. (2018). Mobile Tools for Literacy Learning across the Curriculum in Primary Schools. Mobile Technologies in Children's Language and Literacy: Innovative Pedagogy in Preschool and Primary Education, 99.

[4]. Domingo, M. G., \& Garganté, A. B. (2016). Exploring the use of educational technology in primary education: Teachers' perception of mobile technology learning impacts and applications' use in the classroom. Computers in Human Behavior, 56, 21-28.

[5]. Saranya, S. M., \& Vijayalakshmi, M. (2011, June). Interactive mobile live video learning system in cloud environment. In 2011 International Conference on Recent Trends in Information Technology (ICRTIT) (pp. 673-677). IEEE.
[6]. Fok, W. W., Wong, I. H. M., Tam, V., Yi, J., Auyeung, H. H., \& Law, K. Y. (2014, July).Multidimensionna Disscussions on an Interactive Mobile Platform for language EducationA Case at the University of Hong Kong .In 2014 IEEE 14thInternational Conference on Advance Learning.

[7]. Republic Act No. 10533 - Enhanced Basic Education Act of 2013. Retrieved from www.officialgazette.gov.ph/ 